\title{
Electrodeposition and Characterization of Lanthanide Elements on Carbon Sheets
}

\author{
Min Hee Joo ${ }^{1,2}$, So Jeong Park ${ }^{1}$, Sung-Min Hong ${ }^{1,2}$, Choong Kyun Rhee ${ }^{1}$, Dongsoo Kim ${ }^{3,4, *}$ \\ and Youngku Sohn $1,2, * \mathbb{E}$
}

1 Department of Chemistry, Chungnam National University, Daejeon 34134, Korea; wnalsgm14803@naver.com (M.H.J.); jsjs5921@naver.com (S.J.P.); qwqe212@naver.com (S.-M.H.); ckrhee@cnu.ac.kr (C.K.R.)

2 Department of Chemical Engineering and Applied Chemistry, Chungnam National University, Daejeon 34134, Korea

3 Convergence Research Center for Development of Mineral Resources, Korea Institute of Geoscience and Mineral Resources, 124, Gwahakro, Daejeon 34132, Korea

4 Powder and Ceramics Division, Korea Institute of Materials Science, 797, Changwondaero, Seongsangu, Changwon, Gyeongnam 51508, Korea

* $\quad$ Correspondence: dskim69@kigam.re.kr (D.K.); youngkusohn@cnu.ac.kr (Y.S.); Tel.: +82-42-821-6548 (Y.S.)

\section{check for}

updates

Citation: Joo, M.H.; Park, S.J.; Hong, S.-M.; Rhee, C.K.; Kim, D.; Sohn, Y. Electrodeposition and Characterization of Lanthanide Elements on Carbon Sheets. Coatings 2021, 11, 100. https://doi.org/10.3390/coatings 11010100

Received: 27 December 2020

Accepted: 13 January 2021

Published: 18 January 2021

Publisher's Note: MDPI stays neutral with regard to jurisdictional claims in published maps and institutional affiliations.

Copyright: (c) 2021 by the authors. Licensee MDPI, Basel, Switzerland. This article is an open access article distributed under the terms and conditions of the Creative Commons Attribution (CC BY) license (https:/ / creativecommons.org/licenses/by/ $4.0 /)$.
Abstract: Electrochemical coating and recovery by electrodeposition have been invaluably employed for facial thin film fabrication and the recycling of used materials. Herein, we have established a full data set of lanthanide (Ln: La, Ce, Pr, Nd, Sm, Eu, Gd, Tb, Dy, Ho, Er, Tm, and Yb) elements electrodeposited on carbon sheets. Cyclic voltammetry was performed for $10 \mathrm{mM} \operatorname{Ln}(\mathrm{III})$ ions in a $0.1 \mathrm{M} \mathrm{NaClO}_{4}$ electrolyte over a carbon sheet between $+0.5 \mathrm{~V}$ and $-1.7 \mathrm{~V}$ (vs. $\mathrm{Ag} / \mathrm{AgCl}$ ). Amperometry was performed at a given potential to electrodeposit the Ln element on the carbon sheet. Their physicochemical properties were fully investigated by scanning electron microscopy, Fouriertransform infrared spectroscopy, energy-dispersive X-ray spectroscopy, and X-ray photoelectron spectroscopy. The newly established full data set for $\mathrm{Ln}(\mathrm{III})$ ions over carbon electrodes provides useful fundamental information for the development of coating and recovery methods of Ln elements.

Keywords: lanthanide; electrodeposition; coating; amperometry; cyclic voltammetry; recovery; X-ray photoelectron spectroscopy; carbon sheet

\section{Introduction}

Lanthanide (Ln) elements have been studied extensively in diverse industrial applications of magnets, high- $k$ gate dielectrics, display materials, catalysts, and batteries [1-6]. For recycling used Ln materials, various recovery methods for Ln elements have also been demonstrated [7-13]. In nuclear oxide fuels, Ln elements and actinide (An) elements are commonly co-present, and their redox behaviors are very similar. For this reason, the electrochemical redox behaviors of Ln ions have been studied extensively for the development of reprocessing technology (e.g., pyroprocessing technology) of used nuclear fuels [14,15]. For their studies of electrochemical behaviors and electrodeposition, Thomas et al. successfully demonstrated that silicon-terbium nanowires could be prepared using a one-step electrodeposition method in an electrolyte containing an ionic liquid of 1-butyl-1-methylpyrrolidinium bis(trifluoromethanesulfonyl)imide, $10 \mathrm{mM} \mathrm{SiCl}_{4}$, and $10 \mathrm{mM} \mathrm{TbCl}_{3}$ [2]. Song et al. demonstrated $\mathrm{Ni}-\mathrm{P}-\mathrm{ZrO}{ }_{2}-\mathrm{CeO}_{2}$ composite coatings on \#45 steel using the jet-electrodeposition technique and achieved an optimal coating condition (e.g., potential and current density) for improving surface properties, hardness, and wear resistance [16]. Bourbos et al. studied the recovery of neodymium $(\mathrm{Nd})$ by galvanostatic electrolysis at $-0.8 \mu \mathrm{A}$ and potentiostatic electrolysis at $-2 \mathrm{~V}$ in dimethyl sulfoxide with dissolved $0.1 \mathrm{M} \mathrm{NdCl}_{3}$, where the best result was obtained by pulsed electrolysis at low temperatures under stirring [17]. Li et al. prepared a Ni-Mo-La composite using electro-codeposition in a weak alkaline solution of $\mathrm{Ni}$ and $\mathrm{Mo}$ 
ions mixed with $\mathrm{La}^{3+}$ ion [18]. They observed that the $\mathrm{OH}^{-}$ions were reduced during the electrodeposition, and the reduction potential of $\mathrm{Ni}$ ions was negatively shifted upon addition of La and Mo ions, accompanying a peak broadening and reducing the current efficiency. Park et al. demonstrated that Eu elements could be efficiently recovered on indium-tinoxide electrodes from a $10 \mathrm{mM} \mathrm{Eu}$ (III) $/ 0.1 \mathrm{M} \mathrm{NaClO}_{4}$ electrolyte using the amperometry method [19]. They showed that the as-recovered material was $\mathrm{EuSO}_{4}$, which was phasetransformed to red-luminescent Eu oxysulfate $\left(\mathrm{Eu}_{2} \mathrm{O}_{2} \mathrm{SO}_{4}\right)$ upon thermal annealing at $700{ }^{\circ} \mathrm{C}$. Joo et al. demonstrated that Ln elements could be efficiently coated on $\mathrm{Ni}$ sheets using the amperometry method in a $10 \mathrm{mM} \mathrm{Ln}(\mathrm{III}) / 0.1 \mathrm{M} \mathrm{NaClO}_{4}$ electrolyte [20]. They tentatively concluded that the recovered materials were of a $\mathrm{Ln}_{2}(\mathrm{OH})_{x}\left(\mathrm{CO}_{3}\right)_{y-z}\left(\mathrm{ClO}_{4}\right)_{z} \cdot n \mathrm{H}_{2} \mathrm{O}$ complex. Metal oxides and hydroxides with diverse morphologies including nanowires and nanotubes have been synthesized extensively by electrochemical methods [21-23]. As discussed, many studies on recovery and coating by electrodeposition have been focused on obtaining optimal experimental conditions.

Although there have been many studies for the preparation of Ln-containing materials and their application demonstration tests, few literatures have been systematically studied in view of electrodeposition and recovery of all of the Ln elements over carbon electrodes. In the present study, we employed all of the Ln(III) metal ions in an electrolyte and electrodeposited on carbon sheet electrodes. The novelty of this work is that we first established a full data set for Ln elements on electrochemical behaviors in an $\mathrm{NaClO}_{4}$ electrolyte and the fundamental physicochemical properties of the electrodeposited Ln materials (with presumably $\mathrm{Ln}\left(\mathrm{CO}_{3}\right)_{x}\left(\mathrm{ClO}_{4}\right)_{y}(\mathrm{OH})_{\mathrm{Z}} \cdot \mathrm{nH}_{2} \mathrm{O}$ complex form $)$ on carbon sheets, examined by scanning electron microscopy, Fourier-transform infrared spectroscopy (FT-IR), energy-dispersive X-ray spectroscopy (EDXS), and X-ray photoelectron spectroscopy (XPS). This new data set for Ln elements could be very useful for predicting redox behaviors of $\mathrm{Ln}$ (or An) elements in solutions, improving electrochemical coating technology for Ln elements, and developing treatment (or recycling) technology dealing with Ln elements with similar redox behaviors.

\section{Materials and Methods}

$\mathrm{Ln}$ (III) ion chemicals were all nitrates of $\mathrm{La}(\mathrm{III})$ nitrate hexahydrate $(99.999 \%$, SigmaAldrich, Saint Louis, MO, USA), Ce (III) nitrate hexahydrate (99\%, Sigma-Aldrich), Pr(III) nitrate pentahydrate (99.9\%, Alfa Aesar, Ward Hill, MA, USA), Nd(III) nitrate hexahydrate (99.9\%, Alfa Aesar), Sm(III) nitrate hexahydrate (99.9\%, Alfa Aesar), Eu(III) nitrate hexahydrate (99.9\%, Alfa Aesar), Gd(III) nitrate hexahydrate (99.9\%, Sigma-Aldrich), Tb(III) nitrate hydrate (99.9\%, Alfa Aesar), Dy(III) nitrate pentahydrate (99.9\%, Sigma-Aldrich), Ho(III) nitrate pentahydrate $(99.99 \%$, Alfa Aesar), Er(III) nitrate hydrate $(99.9 \%$, SigmaAldrich), Tm(III) nitrate hydrate $(99.9 \%$, Alfa Aesar), and $\mathrm{Yb}$ (III) nitrate hydrate $(99.9 \%$, Sigma Aldrich), used as received. Carbon sheets (1 mM thick) were used, with a size of $5 \mathrm{mM} \times 20 \mathrm{mM}$. Sodium perchlorate $\left(\mathrm{NaClO}_{4}, \geq 98.0 \%\right.$, Sigma-Aldrich) was used as a supporting electrolyte material and made to an aqueous $0.1 \mathrm{M}$ solution. A $10 \mathrm{mM}$ concentration of $\operatorname{Ln}(\mathrm{III})$ ion in the $0.1 \mathrm{M}$ supporting electrolyte was prepared for electrodeposition. A conventional three-electrode system was used to perform cyclic voltammetry (CV) tests in a blank $0.1 \mathrm{M} \mathrm{NaClO}_{4}$ electrolyte with and without $10 \mathrm{mM} \mathrm{Ln}(\mathrm{III})$ ions using a WPG100 potentiostat/galvanostat (WonATech Co., Ltd., Seoul, Korea) electrochemical workstation. $\mathrm{An} \mathrm{Ag} / \mathrm{AgCl}(3.5 \mathrm{M} \mathrm{KCl})$ electrode, a Pt wire $(0.5 \mathrm{mM})$, and a carbon sheet $(5 \mathrm{~mm} \times 20 \mathrm{mM})$ were used as reference, counter, and working electrodes, respectively. For electrodeposition of the Ln elements on a carbon sheet, the amperometry was conducted at a fixed potential for $5 \mathrm{~h}$ based on the $\mathrm{CV}$ data. After electrodeposition, the electrode was gently removed from the electrolyte, washed with deionized water, and dried under an infrared lamp before further characterization. The surface morphologies of the Lnelectrodeposited samples were examined using a field-emission Hitachi S-4800 scanning electron microscope (FE-SEM, Hitachi Ltd., Tokyo, Japan). For the analysis of elements, energy-dispersive X-ray spectroscopy (EDXS) data were obtained using a JSM $7000 \mathrm{~F}$ scanning electron microscope (JEOL Ltd., Tokyo, Japan) at $20 \mathrm{kV}$. To examine functional 
groups of the electrodeposited materials, FT-IR spectra were obtained using a Nicolet iS 10 FT-IR spectrometer (Thermo Scientific Korea, Seoul, Korea) with an attenuated total reflection mode. For Eu-electrodeposited samples, photoluminescence (PL) emission and excitation spectra were obtained using a Sinco FS-2 fluorescence spectrometer (Sinco, Seoul, Korea). The 2D/3D PL contour profiles were plotted with the emission profiles at various excitation wavelengths. X-ray photoelectron spectra were obtained using a Thermo-VG Scientific K-alpha ${ }^{+}$spectrometer (Thermo VG Scientific, Waltham, MA, USA) equipped with a hemispherical energy analyzer (CAE mode, pass energy $=50.0 \mathrm{eV}$, and step size $=0.100 \mathrm{eV}$ ) and an $\mathrm{Al} \mathrm{K} \alpha \mathrm{X}$-ray source.

\section{Results and Discussion}

Before the electrodeposition of Ln elements on carbon sheets, cyclic voltammetry (CV) data were obtained for $\mathrm{Ln}(\mathrm{III})(\mathrm{La}, \mathrm{Ce}, \mathrm{Pr}, \mathrm{Nd}, \mathrm{Sm}, \mathrm{Eu}, \mathrm{Gd}, \mathrm{Tb}, \mathrm{Dy}, \mathrm{Ho}, \mathrm{Er}, \mathrm{Tm}$, and $\mathrm{Yb}$ ) ions in a blank and $10 \mathrm{mM} \mathrm{Ln(III)} \mathrm{ion} \mathrm{containing} 0.1 \mathrm{M} \mathrm{NaClO}_{4}$ electrolytes. Figure 1 shows the selected CV cycles for $\mathrm{La}$ and Eu ions, and others are provided in the Supplemental Information (Figure S1). For the cyclic voltammetry curve in a blank electrolyte, no critical redox peaks appeared between -1.7 and $+0.5 \mathrm{~V}$ (vs. $\mathrm{Ag} / \mathrm{AgCl})$. The current increase in the negative-going scan was attributed to the current of hydrogen eVolution reaction [24]. In addition, the $\mathrm{CV}$ profile showed high non-faradaic capacitive current, commonly observed in carbon-based materials [25]. For the CV profiles in $10 \mathrm{mM} \mathrm{Ln}(\mathrm{III}) / 0.1 \mathrm{M} \mathrm{NaClO}_{4}$ electrolytes, a critical difference in $\mathrm{CV}$ was observed in the high negative potential region, compared with the $\mathrm{CV}$ obtained in a blank $0.1 \mathrm{M} \mathrm{NaClO}_{4}$ electrolyte. A curvature generally appeared between -1.3 and $-1.5 \mathrm{~V}(\mathrm{vs}$. $\mathrm{Ag} / \mathrm{AgCl}$ ), which was attributed to a reduction potential forming a complex [20], discussed further below. The observed potentials for the Ln(III) ions appeared at similar potentials. There was no corresponding oxidation peak in the opposite potential scan. This could be because the curvature in the high potential region was due to an irreversible process [19]. Once a complex was formed in the negative-going scan, the insoluble element was not returned into an electrolyte during the opposite positive-going scan. Interestingly, the CV profile in $10 \mathrm{mM} \mathrm{Eu(III)/0.1} \mathrm{M}$ $\mathrm{NaClO}_{4}$ electrolyte was critically different from those of other Ln ions. Two redox peaks were observed at $-0.82 \mathrm{~V}$ and $+0.40 \mathrm{~V}$, tentatively attributed to $\mathrm{Eu}(\mathrm{III})+\mathrm{e}^{-} \rightarrow \mathrm{Eu}(\mathrm{II})$ and $\mathrm{Eu}(\mathrm{II}) \rightarrow \mathrm{Eu}(\mathrm{III})+\mathrm{e}^{-}$reactions, respectively [19].
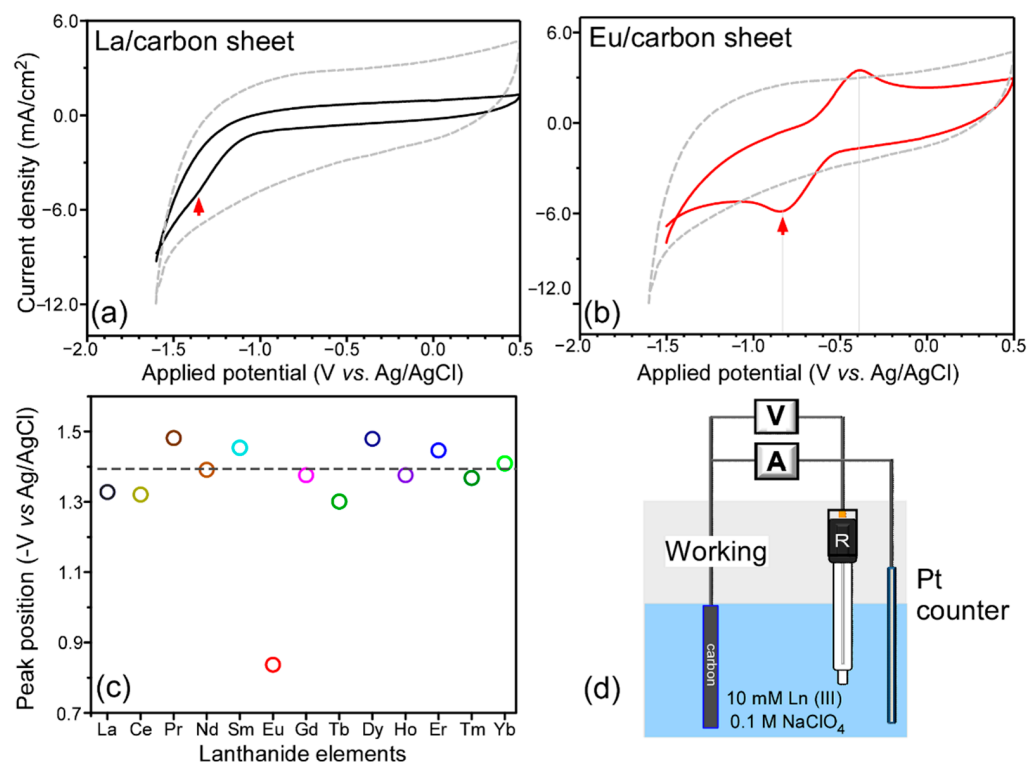

Figure 1. Cyclic voltammetry profiles for (a) $10 \mathrm{mM} \mathrm{La(III)} \mathrm{and} \mathrm{(b)} \mathrm{Eu}$ (III) ions in $0.1 \mathrm{M} \mathrm{NaClO}_{4}$ electrolyte on carbon sheets at a scan rate of $200 \mathrm{mV} \cdot \mathrm{s}^{-1}$, (c) reduction peak positions with Ln elements, and (d) a schematic of a three-electrode system. Newly appeared curvature is indicated by a red arrow. 
Amperometry was performed at a fixed potential in $10 \mathrm{mM} \mathrm{Ln}(\mathrm{III}) / 0.1 \mathrm{M} \mathrm{NaClO}_{4}$ electrolytes for $5 \mathrm{~h}$ to electrodeposit the Ln elements on carbon sheets. The surface morphologies of the electrodeposited Ln materials were fully examined by SEM, displayed in Figure 2. The SEM images (Figure 2B-N) of all of the Ln-deposited samples were observed to be critically different from that of a bare carbon sheet (Figure 2A). This indicates that Ln materials were recovered (or electrodeposited) on the carbon sheets. The optical microscope images also showed a clear distinction between bare (in Figure 2A1) and electrodeposited (in Figure 2L1) samples. We also observed precipitates in the electrolyte after electrodeposition (bottom panel in Figure 2) due to fall by gravity during electrodeposition. The morphologies in the SEM images showed aggregated particles, smooth thin films, or cluster-like thin-film states. The thicknesses of the electrodeposited samples and the amounts of precipitates in the electrolyte were found to be dependent on the Ln element. For the SEM image of Pr-electrodeposited samples, the surface morphology showed a very continuous uniform film state. As the atomic number increased from $\mathrm{La}(\# 57)$ to $\mathrm{Yb}(\# 70)$, the morphology changed from a film state to a nanoparticle-cluster state. For $\mathrm{Ho}$, Er, and $\mathrm{Yb}$ samples, the morphologies appeared as clusters aggregated with small nanoparticles.

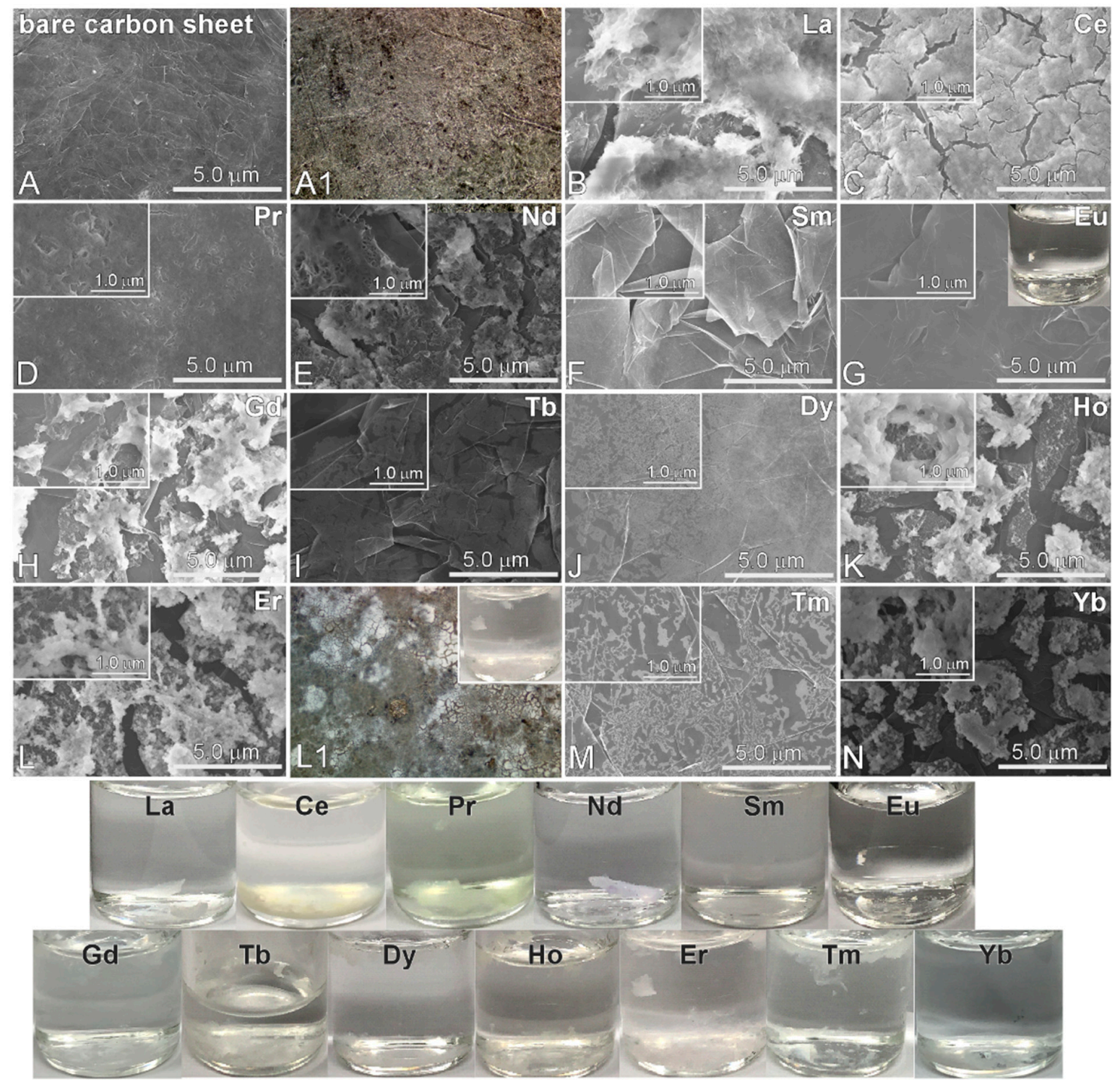

Figure 2. Scanning electron microscope images (A-N) for a bare carbon sheet (A) and electrodeposited Ln elements on carbon sheet electrodes $(\mathbf{B}-\mathbf{N})$, optical microscope $(300 \times)$ images $(\mathbf{A 1}, \mathbf{L 1})$, and the corresponding photos (bottom panel) of electrolytes (with precipitates) after electrodeposition. 
Energy-dispersive X-ray spectroscopy (EDXS) data were obtained to examine the elements of electrodeposited Ln materials on carbon sheets in Figure 3. In the EDX spectra, four common elements of $\mathrm{C}, \mathrm{O}, \mathrm{Na}$, and $\mathrm{Cl}$ were observed at $0.26 \mathrm{KeV}(\mathrm{C} \mathrm{K})$ and $0.52 \mathrm{KeV}$ $(\mathrm{O} \mathrm{K}), 1.04 \mathrm{KeV}(\mathrm{Na} \mathrm{K})$, and $2.63 \mathrm{KeV}(\mathrm{Cl} \mathrm{K})$, respectively [26]. The $\mathrm{Na} \mathrm{K}$ signal was due to trapped $\mathrm{Na}$ ions from the $\mathrm{NaClO}_{4}$ electrolyte. The $\mathrm{Cl} \mathrm{K}$ signal was attributed to $\mathrm{ClO}_{4}$ species. The strongest $\mathrm{C} \mathrm{K}$ signal at $0.26 \mathrm{KeV}$ was mainly due to the carbon support electrode and partly due to carbon-based complex species. Upon electrodeposition of Ln elements, several peaks (Ln M and Ln L) newly appeared. The Ln M and Ln L peak positions were observed to be shifted to higher energy positions as the atomic number was increased. For the EDXS of La-electrodeposited samples, the Ln M peak was observed at $0.83 \mathrm{KeV}$. Two La L signals were observed at $4.64 \mathrm{KeV}$ and $5.04 \mathrm{KeV}$. For the EDXS of $\mathrm{Yb}$-electrodeposited samples, the $\mathrm{Yb} \mathrm{M}$ peak was observed at $1.53 \mathrm{KeV}$. Two $\mathrm{Yb} \mathrm{L}$ signals were observed at $7.40 \mathrm{KeV}$ and $8.39 \mathrm{KeV}$. The peak separation of the $\mathrm{La} \mathrm{M}$ and the $\mathrm{Yb}$ $\mathrm{M}$ signals was estimated to be $0.7 \mathrm{KeV}$. We could not measure a EDXS for radioactive promethium (Pm), but the Pm M and Pm L signals could be expected from the plots in Figure 3.

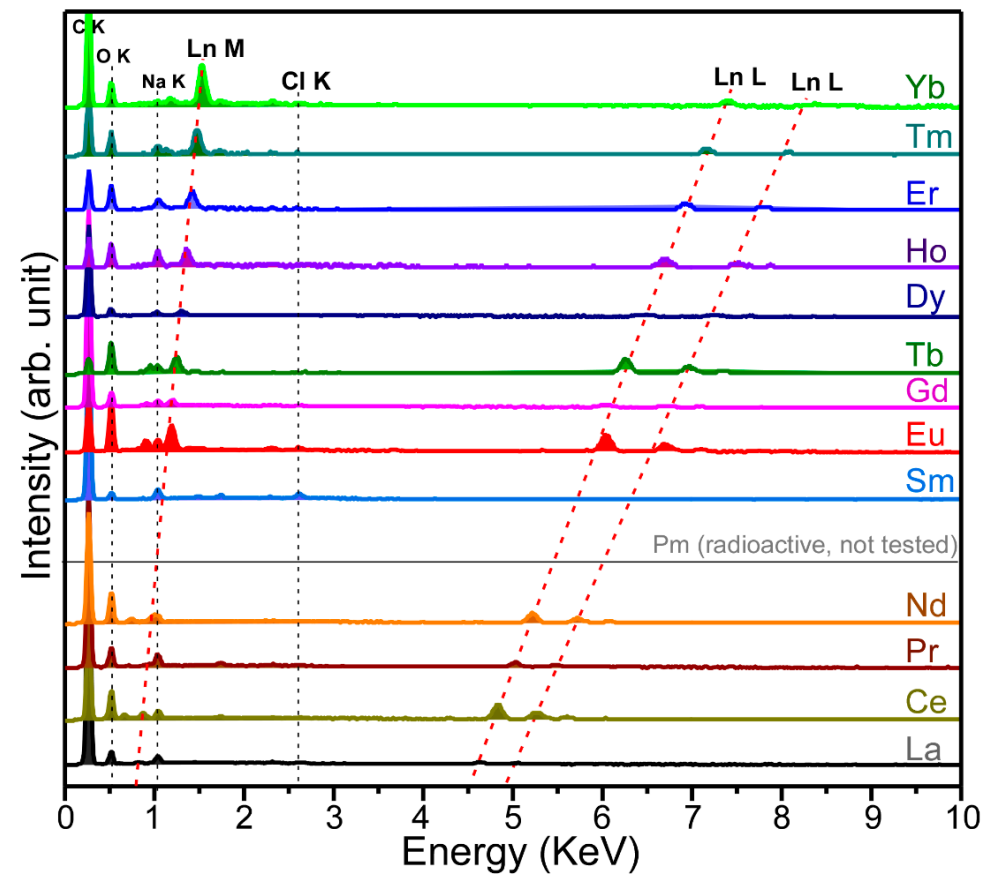

Figure 3. EDXS profiles for electrodeposited Ln elements on carbon sheets.

FT-IR spectra (Figure 4) were obtained to examine main functional groups consisting of the electrodeposited materials. Interestingly, all the FT-IR profiles were found to be very similar, indicating that all of the complexes were of a similar-type material. A broad peak was commonly observed around $3600 \mathrm{~cm}^{-1}$, which was attributed to the $\mathrm{Ln}-\mathrm{OH}$ stretching and $\mathrm{H}_{2} \mathrm{O}$ (hydrated) vibrations $[27,28]$. The $\mathrm{O}-\mathrm{H}$ bending vibrational mode appeared around $1620 \mathrm{~cm}^{-1}$. For the origin of the $\mathrm{OH}$ group, a nitrate reduction process $\left(\mathrm{NO}_{3}+\mathrm{H}_{2} \mathrm{O}\right.$ $\left.+2 \mathrm{e}^{-} \rightarrow \mathrm{NO}_{2}+2 \mathrm{OH}\right)$ was possibly involved in the complexation with $\mathrm{OH}[29,30]$. The Ln-O vibrational modes were commonly observed around $610 \mathrm{~cm}^{-1}$ [28]. Two more FT-IR peaks appeared strongly around 1080 and $1350 \mathrm{~cm}^{-1}$. The former peak around $1080 \mathrm{~cm}^{-1}$ was attributed to the vibration of the $\mathrm{ClO}_{4}{ }^{-}$group [31]. A strong region around $1350 \mathrm{~cm}^{-1}$ appeared to be vibration modes of $\mathrm{CO}_{3}{ }^{2-}$ species [27,28]. Based on the FT-IR data, the electrodeposited samples consisted of $\mathrm{OH}\left(\right.$ and $/$ or $\left.\mathrm{H}_{2} \mathrm{O}\right), \mathrm{CO}_{3}{ }^{2-}$ and $\mathrm{ClO}_{4}{ }^{-}$species that complexed with central Ln ions. Joo et al. reported similar FT-IR profiles for electrodeposition Ln materials on Ni sheets [20]. They concluded that the electrodeposited materials had a $\mathrm{RE}_{2}(\mathrm{OH})_{x}\left(\mathrm{CO}_{3}\right)_{y-z}\left(\mathrm{ClO}_{4}\right)_{z} \cdot n \mathrm{H}_{2} \mathrm{O}$ complex. For the complex form in the present 
study, meaningful X-ray diffraction signals could not be obtained, plausibly due to poor crystallinity. Based on the literature [20] and the corresponding FT-IR data, we tentatively concluded that the electrodeposits were a $\mathrm{Ln}\left(\mathrm{CO}_{3}\right)_{x}\left(\mathrm{ClO}_{4}\right)_{y}(\mathrm{OH})_{z} \cdot n \mathrm{H}_{2} \mathrm{O}$ complex form.

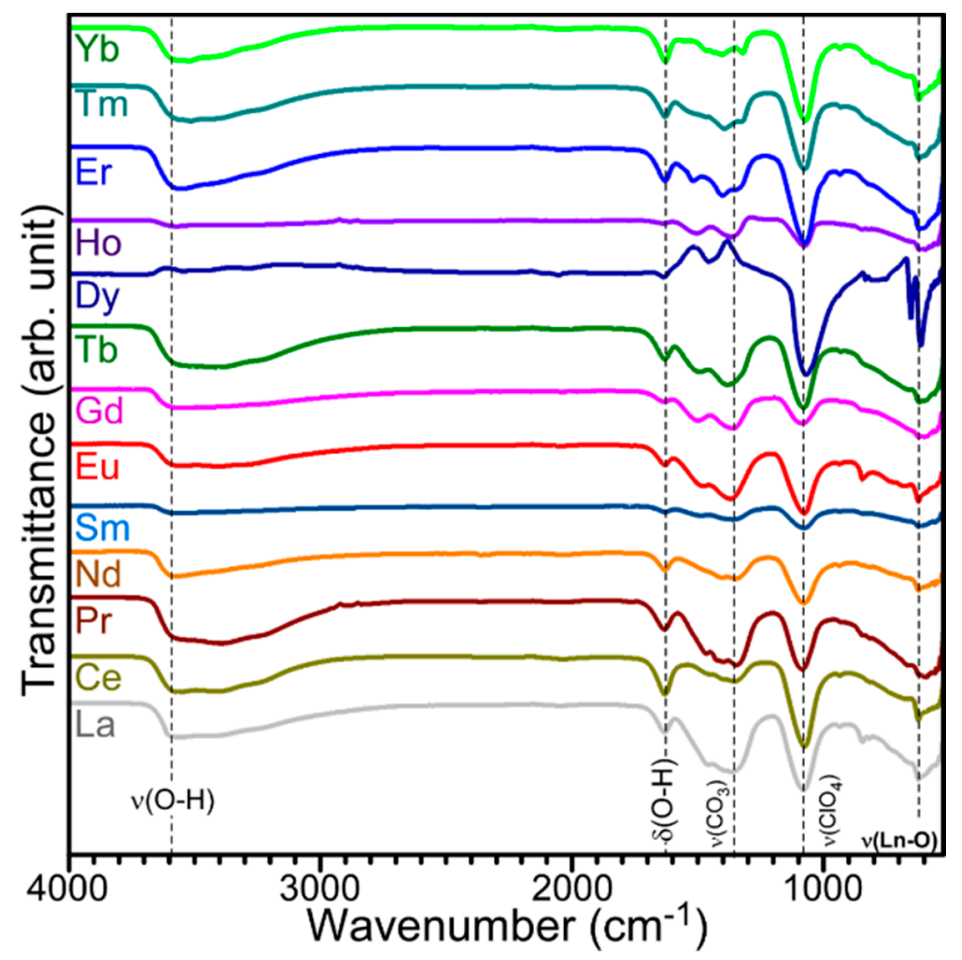

Figure 4. Transmittance FT-IR profiles for electrodeposited Ln elements on carbon sheets.

XPS data (Figure 5) were obtained to examine surface chemical states of the electrodeposited Ln elements and confirm the Ln recovery on carbon sheets. For the La 3d XPS profile, four peaks were observed, and the $\mathrm{La} 3 \mathrm{~d}_{5 / 2}$ and $\mathrm{La} 3 \mathrm{~d}_{3 / 2}$ peaks were observed at $834.8 \mathrm{eV}$ and $851.6 \mathrm{eV}$, respectively, with a spin-orbit splitting energy of $16.8 \mathrm{eV}$. The binding energy position is in good agreement with the $\mathrm{La}(\mathrm{III})$ oxidation state. Two additional peaks at $838.5 \mathrm{eV}$ and $855.2 \mathrm{eV}$ were commonly attributed to the final state peak [32]. For Ce $3 \mathrm{~d}$ XPS profile, the Ce $3 \mathrm{~d}_{5 / 2}$ and Ce $3 \mathrm{~d}_{3 / 2}$ peaks were observed at $882.4 \mathrm{eV}$ and $900.8 \mathrm{eV}$, respectively, with a spin-orbit splitting energy of $18.4 \mathrm{eV}$, in good agreement with the $\mathrm{Ce}(\mathrm{IV})$ oxidation state. The characteristic of Ce(IV) XPS peaks was also observed at $888.8 \mathrm{eV}\left(\mathrm{u}_{2}\right)$, $898.3 \mathrm{eV}\left(\mathrm{u}_{3}\right), 907.3 \mathrm{eV}\left(\mathrm{v}_{2}\right)$, and $916.6 \mathrm{eV}\left(\mathrm{v}_{3}\right)$ [33]. The XPS peaks $\left(\mathrm{u}_{1}\right.$ and $\left.\mathrm{v}_{1}\right)$ of the $\mathrm{Ce}(\mathrm{III})$ oxidation state were hardly detectable. For the $\operatorname{Pr} 3 d$ XPS profile, the $\operatorname{Pr} 3 d_{5 / 2}$ and $\operatorname{Pr} 3 d_{3 / 2}$ peaks were observed at $933.2 \mathrm{eV}$ and $953.7 \mathrm{eV}$, respectively, with a spin-orbit splitting energy of $20.5 \mathrm{eV}$, due to the $\operatorname{Pr}(\mathrm{III})$ oxidation state [34]. The corresponding shoulder peaks around $929.0 \mathrm{eV}$ and $949.2 \mathrm{eV}$ were attributed satellite peaks [34]. For the Nd 3d XPS profile, the $\mathrm{Nd} 3 \mathrm{~d}_{5 / 2}$ and $\mathrm{Nd} 3 \mathrm{~d}_{3 / 2}$ peaks were observed at $981.9 \mathrm{eV}$ and $1004.4 \mathrm{eV}$, respectively, with a spin-orbit splitting energy of $22.5 \mathrm{eV}$, due to the $\mathrm{Nd}(\mathrm{III})$ oxidation state [35]. The asymmetric shoulder peaks were attributed to multiplet splitting of $\mathrm{Nd}(\mathrm{III})$, as observed in the Pr $3 d$ XPS profile $[34,35]$. For the Sm $3 d$ XPS profile, the $S m 3 d_{5 / 2}$ and $S m 3 d_{3 / 2}$ peaks were observed at $1082.9 \mathrm{eV}$ and $1109.9 \mathrm{eV}$, respectively, with a spin-orbit splitting energy of $27.0 \mathrm{eV}$, attributed to the Sm(III) oxidation state [36]. For the Eu 3d XPS profile, the Eu $3 d_{5 / 2}$ and Eu $3 d_{3 / 2}$ peaks were observed at $1134.6 \mathrm{eV}$ and $1164.3 \mathrm{eV}$, respectively, with a spin-orbit splitting energy of $29.7 \mathrm{eV}$, due to the Eu(III) oxidation state [37]. An Eu(II) oxidation state was not significantly observed. For the Gd $3 d$ XPS profile, the $G d 3 d_{5 / 2}$ and $\mathrm{Gd} 3 \mathrm{~d}_{3 / 2}$ peaks were positioned at $1186.9 \mathrm{eV}$ and $1219.2 \mathrm{eV}$, respectively, with a spin-orbit splitting energy of $32.3 \mathrm{eV}$, due to the $\mathrm{Gd}(\mathrm{III})$ oxidation state [28]. For the Tb $3 \mathrm{~d}$ XPS profile, the $\mathrm{Tb} 3 \mathrm{~d}_{5 / 2}$ and $\mathrm{Tb} 3 \mathrm{~d}_{3 / 2}$ peaks were positioned at $1241.5 \mathrm{eV}$ and $1276.1 \mathrm{eV}$, respectively, 
with a spin-orbit splitting energy of $34.6 \mathrm{eV}$, due to the $\mathrm{Tb}(\mathrm{III})$ oxidation state [38]. For the Dy $3 \mathrm{~d}$ XPS profile, the Dy $3 \mathrm{~d}_{5 / 2}$ and Dy $3 \mathrm{~d}_{3 / 2}$ peaks were positioned at $1296.6 \mathrm{eV}$ and $1334.5 \mathrm{eV}$, respectively, with a spin-orbit splitting energy of $37.9 \mathrm{eV}$, due to the Dy(III) oxidation state [39]. Broad Ho 4d, Er 4d, Tm 4d, and $\mathrm{Yb} 4 \mathrm{~d}$ XPS peaks were observed at BEs of $162.4 \mathrm{eV}, 168.2 \mathrm{eV}, 176.4 \mathrm{eV}$, and $158.2 \mathrm{eV}$, respectively [40-43]. The plot for the $3 \mathrm{~d}_{5 / 2,3 / 2}$ spin-orbit splitting energies showed a linear relationship with atomic number from La (\# 57) to Dy (\#66).

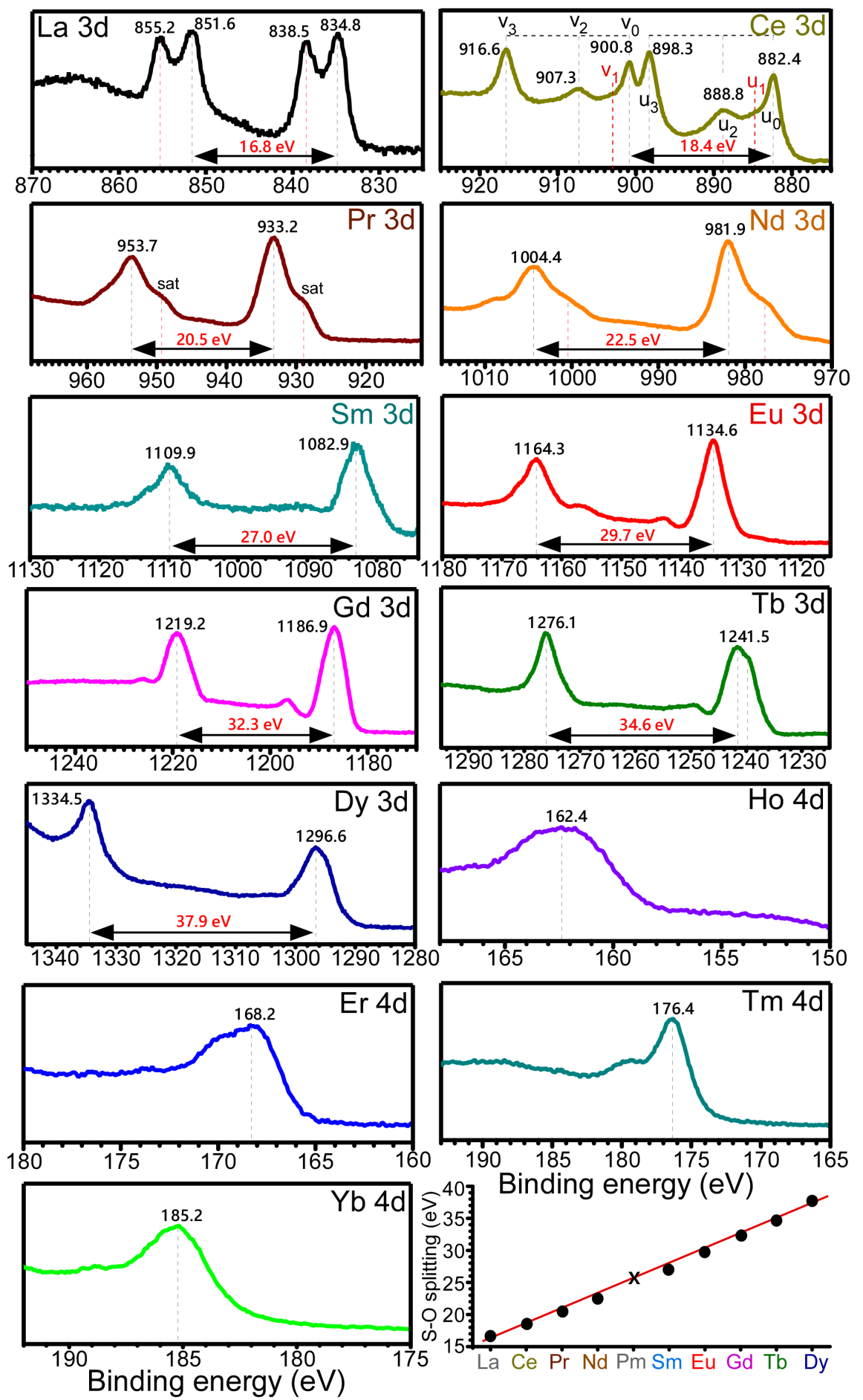

Figure 5. La 3d, Ce 3d, Pr 3d, Nd 3d, Sm 3d, Eu 3d, Gd 3d, Tb 3d, Dy 3d, Ho 4d, Er 4d, Tm 4d, and $\mathrm{Yb} 4 \mathrm{~d}$ XPS profiles, and the $3 \mathrm{~d}_{5 / 2,3 / 2}$ spin-orbit splitting energies. 
Carbon and oxygen were also analyzed using XPS (Figure 6). For the C 1s XPS profiles, a strong C 1s XPS signal was observed at a BE of $284.5 \mathrm{eV}$, attributed to carbon support material. For a bare carbon sheet, a broad peak around $291 \mathrm{eV}$ was attributed to the shakeup of carbon [44]. For electrodeposited samples, a newly appeared peak was observed around $289 \mathrm{eV}$. This could be attributed to $\mathrm{O}-\mathrm{C}=\mathrm{O}$ and $\mathrm{C}=\mathrm{O}$ species of carbonates $[20,38]$, whose FT-IR signal was observed in Figure 4. For the O 1s XPS spectra, a broad peak was commonly observed around $531 \mathrm{eV}$. For the O 1s XPS of the bare carbon sheet, the signal was extremely weak compared to others. The major broad peak could be due to $\mathrm{O}$ of carbonates, complexed (or surface) $\mathrm{OH}$, and hydrated (or surface) $\mathrm{H}_{2} \mathrm{O}[20,38]$. For the $\mathrm{O}$ $1 \mathrm{~s}$ of the Ce-electrodeposited material, an extra peak was observed at $529.4 \mathrm{eV}$, attributed to lattice oxygen of Ce oxide species [33,38].
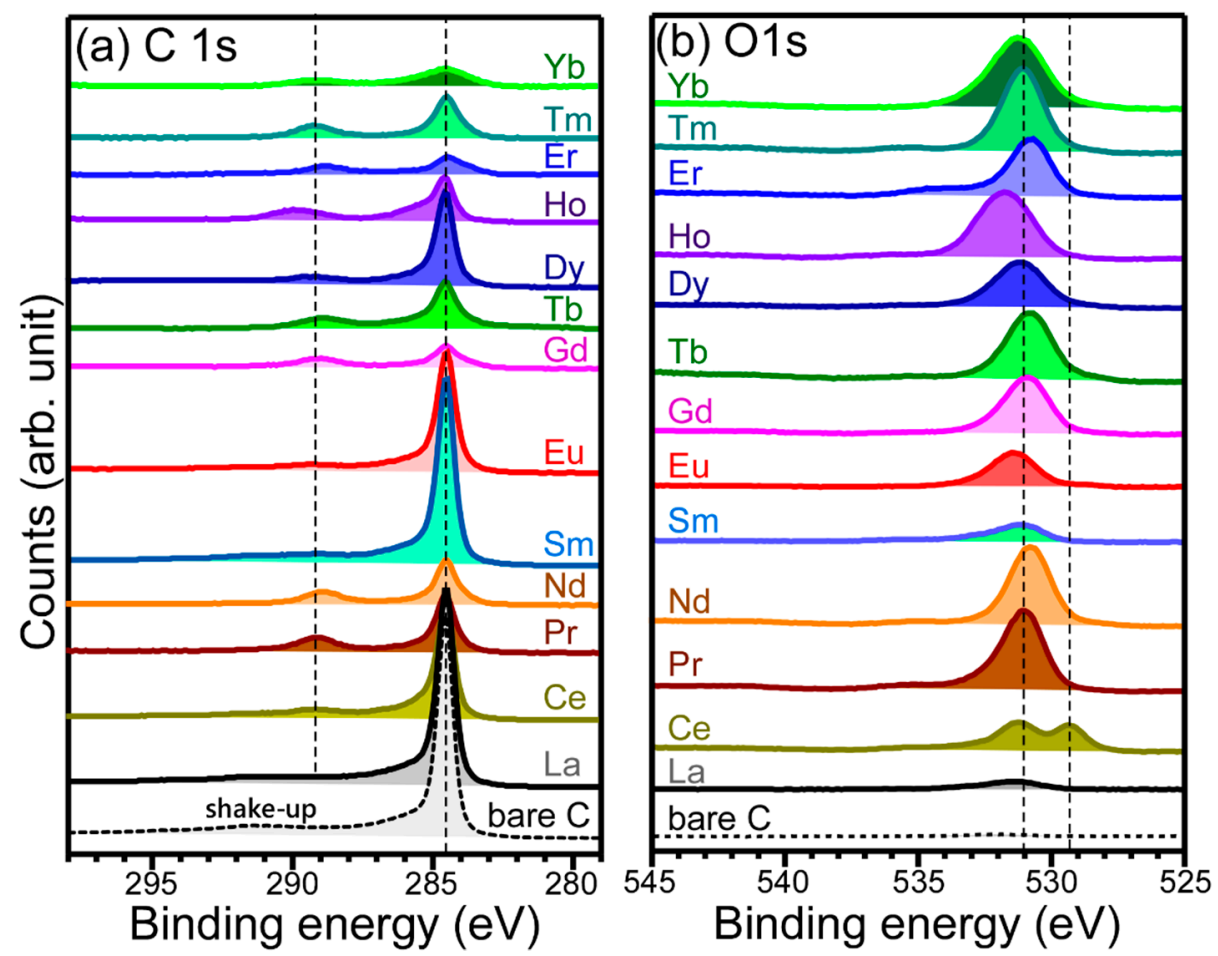

Figure 6. C 1s (a) and O 1s (b) XPS profiles for a bare carbon sheet and electrodeposited Ln elements on carbon sheets.

For electrodeposition, the amount of material on the carbon sheet increases, while the metal ion decreases in the electrolyte, as electrodeposition time increases. As a brief demonstration test, the $10 \mathrm{mM} \mathrm{Ce}(\mathrm{III}) / 0.1 \mathrm{M} \mathrm{NaClO}_{4}$ electrolyte was selected, because $\mathrm{Ce}(\mathrm{III})$ electrolyte shows a broad photoluminescence at an excitation wavelength of $275 \mathrm{~nm}$. As shown in Figure 7, the PL intensity was decreased after electrodeposition. This indicates that Ce ion in the electrolyte was transformed to a complex as thin film (on carbon sheet) or yellow precipitates in the electrolyte (top right panel in Figure 7).

An extra demonstration test was the XPS data obtained for the thermal-annealed Ce-electrodeposited sample. It was clearly observed that the oxidation state was mainly $\mathrm{Ce}(\mathrm{IV})$ for as-electrodeposited samples while the oxidation states were both $\mathrm{Ce}(\mathrm{III})$ and $\mathrm{Ce}(\mathrm{IV})$ [33]. The O 1 s peak of lattice oxygen was shifted from 529.4 to $528.2 \mathrm{eV}$ after thermal annealing. These require further investigation to obtain detailed fundamental information. 


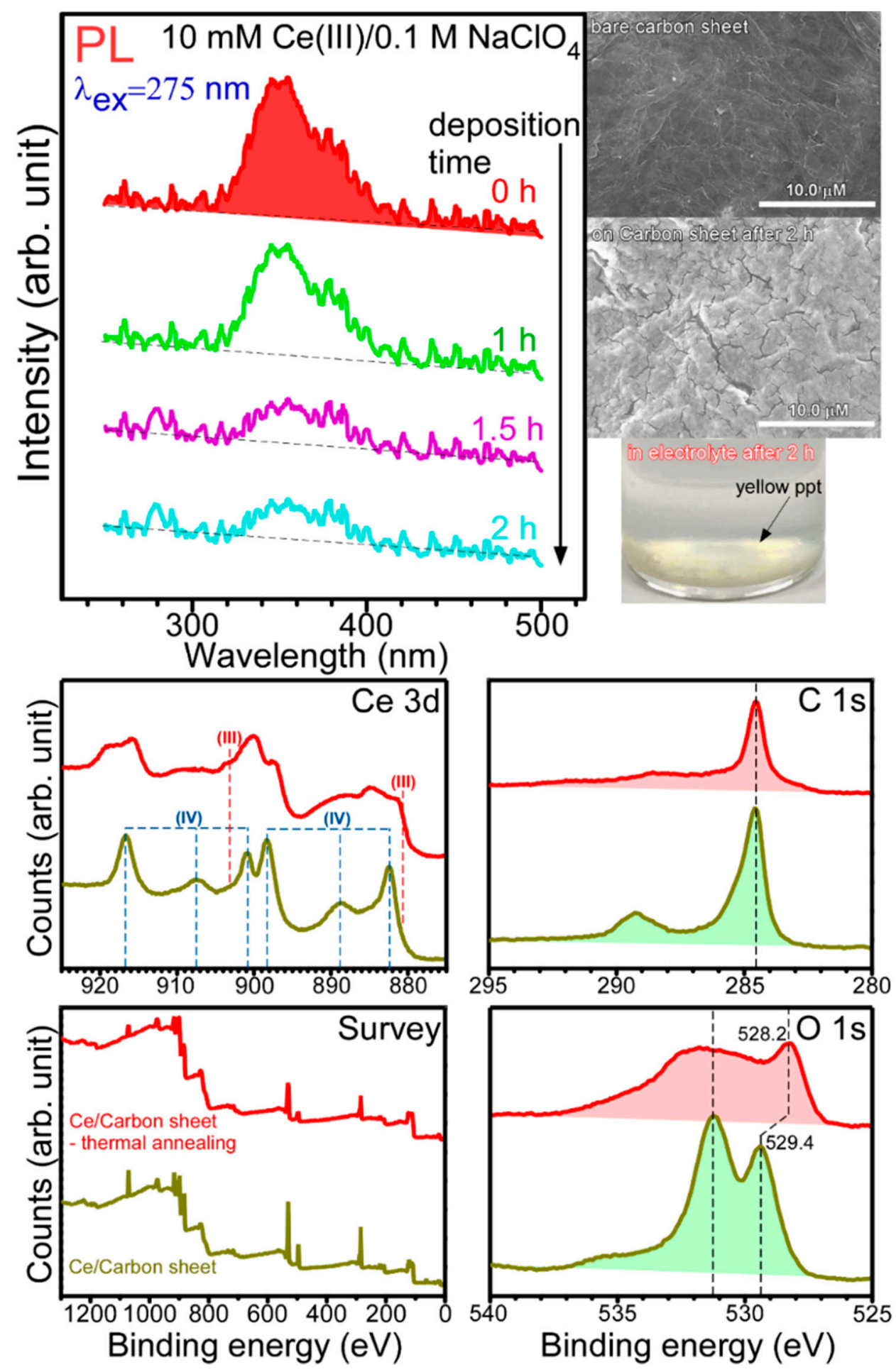

Figure 7. Photoluminescence spectra (top left) of $10 \mathrm{mM} \mathrm{Ce}(\mathrm{III}) / 0.1 \mathrm{M} \mathrm{NaClO}_{4}$ electrolyte with electrodeposition time; SEM images (top right) of the carbon sheet before and after electrodeposition, and a photo of the electrolyte after electrodeposition; and Ce 3d, C 1s, survey, and O 1s XPS profiles before and after thermal annealing at $550{ }^{\circ} \mathrm{C}$.

We employed photoluminescence spectroscopy to further confirm the oxidation state of Ln elements initially probed by XPS above in Figure 5 . Eu element with two oxidation states of $2+$ and $3+$ was selected because Eu(III) ion only exhibits unique ${ }^{5} \mathrm{D}_{0} \rightarrow{ }^{7} \mathrm{~F}_{0,1,2,3,4}$ transitions between 550 and $750 \mathrm{~nm}$. In addition, when the ${ }^{5} \mathrm{D}_{0} \rightarrow{ }^{7} \mathrm{~F}_{2}$ transition is strong, the material with $\mathrm{Eu}(\mathrm{III})$ ion exhibits a red color $[20,37,45]$. On the other hand, $\mathrm{Eu}(\mathrm{II})$ ion 
exhibits a blue color around $400 \mathrm{~nm}$ under UV light excitation [20,37]. Figure 8 displays excitation (setting at $\lambda_{\mathrm{em}}=613 \mathrm{~nm}$ and $590 \mathrm{~nm}$ ) and emission (setting at $\lambda_{\mathrm{ex}}=280 \mathrm{~nm}$, $383 \mathrm{~nm}$, and $395 \mathrm{~nm}$ ) spectra for an Eu-electrodeposited sample. For the excitation spectra (Figure $8 \mathrm{a}$ ), the profiles were very similar, and several sharp peaks were observed around $300 \mathrm{~nm}, 320 \mathrm{~nm}, 365 \mathrm{~nm}, 383 \mathrm{~nm}, 395 \mathrm{~nm}, 415 \mathrm{~nm}$, and $465 \mathrm{~nm}$, attributed to the transitions from the ground ${ }^{7} \mathrm{~F}_{0}$ state of $\mathrm{Eu}(\mathrm{III})$ to the upper ${ }^{5} \mathrm{~F}_{4},{ }^{5} \mathrm{H}_{5},{ }^{5} \mathrm{D}_{4},{ }^{5} \mathrm{G}_{\mathrm{J}} /{ }^{5} \mathrm{~L}_{7},{ }^{5} \mathrm{~L}_{6},{ }^{5} \mathrm{D}_{3}$, and ${ }^{5} \mathrm{D}_{2}$ electronic energy levels, respectively [20,37,45]. It was observed that the signal intensities setting at an emission wavelength of $613 \mathrm{~nm}$ were stronger than those at $590 \mathrm{~nm}$. On the basis of the excitation spectra, three excitation wavelengths $\left(\lambda_{\mathrm{ex}}\right)$ of $395 \mathrm{~nm}, 383 \mathrm{~nm}$, and $280 \mathrm{~nm}$ were selected to obtain emission spectra. Two wavelengths of $395 \mathrm{~nm}$ and $383 \mathrm{~nm}$ correspond to direct transitions of $\mathrm{Eu}(\mathrm{III}): 383 \mathrm{~nm}$ (the ${ }^{5} \mathrm{G}_{\mathrm{J}} /{ }^{5} \mathrm{~L}_{7} \leftarrow{ }^{7} \mathrm{~F}_{0}$ direct excitation) and $395 \mathrm{~nm}$ (the ${ }^{5} \mathrm{~L}_{6} \leftarrow{ }^{7} \mathrm{~F}_{0}$ direct excitation), respectively. As a consequence, the two emission spectra at $\lambda_{\mathrm{ex}}=383 \mathrm{~nm}$ and $395 \mathrm{~nm}$ were very similar in Figure 8b, but the intensities were different, as expected from the corresponding excitation spectrum. The other excitation wavelength of $280 \mathrm{~nm}$ corresponds to an indirect excitation, not direct transition to an electronic energy level of Eu(III). Consequently, the emission profile at $\lambda_{\mathrm{ex}}=280 \mathrm{~nm}$ was dissimilar to the other two at $\lambda_{\mathrm{ex}}=383 \mathrm{~nm}$ and $395 \mathrm{~nm}$. The emission signal was also weaker than those of the other two. The emission signals were commonly observed around $580 \mathrm{~nm}, 590 \mathrm{~nm}, 613 \mathrm{~nm}, 645 \mathrm{~nm}$, and $700 \mathrm{~nm}$, assigned to the transitions from the excited ${ }^{5} \mathrm{D}_{0}$ electronic energy level to the lower ${ }^{7} \mathrm{~F}_{0},{ }^{7} \mathrm{~F}_{1},{ }^{7} \mathrm{~F}_{2},{ }^{7} \mathrm{~F}_{3}$, and ${ }^{7} \mathrm{~F}_{4}$ energy states, respectively $[37,45]$. The emission signal at $613 \mathrm{~nm}\left({ }^{5} \mathrm{D}_{0} \rightarrow{ }^{7} \mathrm{~F}_{2}\right.$ transition) was much stronger than others. As a consequence, the Eu-electrodeposited sample was expected to have appeared red, as shown in the inset photo of Figure $8 \mathrm{a}$. The ${ }^{5} \mathrm{D}_{0} \rightarrow{ }^{7} \mathrm{~F}_{2}$ transition of $\mathrm{Eu}$ (III) has commonly been used to probe $\mathrm{Eu}$ (III) local environment because of the electric dipole transition hypersensitive to local environment [20,37]. When the local symmetry of $\mathrm{Eu}(\mathrm{III})$ ion is high, the ${ }^{5} \mathrm{D}_{0} \rightarrow{ }^{7} \mathrm{~F}_{2}$ transition signal becomes weaker. On the other hand, the signal becomes stronger than other transition signals when $\mathrm{Eu}(\mathrm{III})$ ion is positioned at a low symmetric site. On the basis of the emission signals (Figure 8b), it could be concluded that the $\mathrm{Eu}$ (III) ion has a low symmetry. It is known that the ${ }^{5} \mathrm{D}_{0} \rightarrow{ }^{7} \mathrm{~F}_{1}$ transition is not sensitive to the Eu(III) local environment. The $\left({ }^{5} \mathrm{D}_{0} \rightarrow{ }^{7} \mathrm{~F}_{2}\right) /\left({ }^{5} \mathrm{D}_{0} \rightarrow{ }^{7} \mathrm{~F}_{1}\right)$ intensity ratio is known as an asymmetric ratio reflecting the symmetry of the $\mathrm{Eu}(\mathrm{III})$ local site [20,37]. For direct and indirect excitations, the ratios were estimated to be 1.9 and 0.9 , respectively. The corresponding 2D and 3D-mapping profiles (Figure 8c,d) show the emission signal distributions at all the excitation wavelengths, where the densely spaced regions exhibit strong emission signals. As discussed above, the densely spaced regions correspond to ${ }^{5} \mathrm{D}_{0}$ $\rightarrow{ }^{7} \mathrm{~F}_{0,1,2,3,4}$ emission transitions and the upper energy levels $\left({ }^{5} \mathrm{~F}_{4},{ }^{5} \mathrm{H}_{5},{ }^{5} \mathrm{D}_{4},{ }^{5} \mathrm{G}_{\mathrm{J}} /{ }^{5} \mathrm{~L}_{7},{ }^{5} \mathrm{~L}_{6}\right.$, ${ }^{5} \mathrm{D}_{3}$, and $\left.{ }^{5} \mathrm{D}_{2}\right) \leftarrow{ }^{7} \mathrm{~F}_{0}$ excitation transitions. 


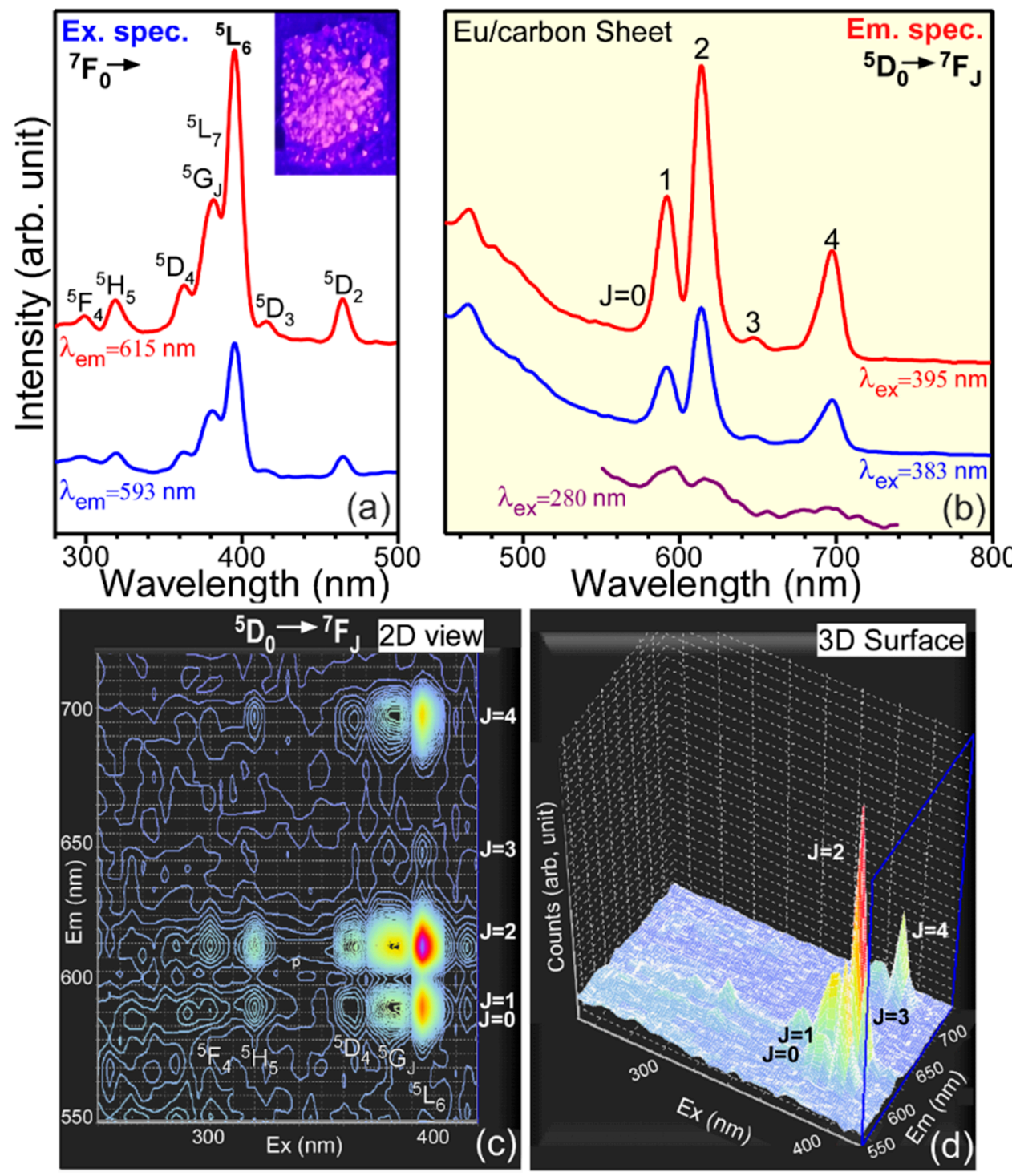

Figure 8. Excitation (a) and emission (b) spectral profiles for electrodeposited Eu on a carbon sheet, and the corresponding 2D and 3D-photoluminescence contour profiles (c,d).

\section{Conclusions}

All of the Ln elements were electrodeposited on carbon sheets using the amperometry method in a $10 \mathrm{mM} \mathrm{Ln}(\mathrm{III}) / 0.1 \mathrm{M} \mathrm{NaClO}_{4}$ electrolyte. For the $\mathrm{CV}$ profiles, a anodic peak generally appeared between -1.3 and $-1.5 \mathrm{~V}$ (vs. $\mathrm{Ag} / \mathrm{AgCl}$ ), which was attributed to a reduction potential forming a complex. No corresponding cathodic peak was observed, an indication of an irreversible process. All of the electrodeposited materials on carbon sheets showed uniform film or clusters aggregated with nanoparticles, depending on the Ln elements. FT-IR spectra showed major functional species of $\mathrm{OH} / \mathrm{H}_{2} \mathrm{O}, \mathrm{CO}_{3}{ }^{2-}$, and $\mathrm{ClO}_{4}{ }^{-}$groups that may form complexes with a central Ln metal ion, presumably $\mathrm{Ln}\left(\mathrm{CO}_{3}\right)_{x}\left(\mathrm{ClO}_{4}\right)_{y}(\mathrm{OH})_{z} \cdot n \mathrm{H}_{2} \mathrm{O}$ complex. EDXS data confirmed $\mathrm{Ln}, \mathrm{C}, \mathrm{O}$, and $\mathrm{Cl}$ elements expected from the FT-IR data. The oxidation states of Ln were fully examined using the XPS data set of all the Ln-electrodeposited materials. Excitation/emission spectra and their 2D/3D contour mapping profiles were obtained for Eu-electrodeposited samples to further confirm the oxidation state. The several emission signals between 570 and $720 \mathrm{~nm}$ were assigned to the ${ }^{5} \mathrm{D}_{0} \rightarrow{ }^{7} \mathrm{~F}_{0,1,2,3,4}$ transitions of the $\mathrm{Eu}(\mathrm{III})$ ion. The high $\left({ }^{5} \mathrm{D}_{0} \rightarrow{ }^{7} \mathrm{~F}_{2}\right) /\left({ }^{5} \mathrm{D}_{0} \rightarrow{ }^{7} \mathrm{~F}_{1}\right)$ intensity ratio reflects that the $\mathrm{Eu}(\mathrm{III})$ ion was positioned at a low local symmetry. For future application study, the electrodeposition method can also be applied to fabricate Ln and carbon-based electrode materials for fuel cells, supercapacitors, 
hydrogen production, and $\mathrm{CO}_{2}$ reduction, with many advantages over other methods, including facial thin film fabrication and uniform coatings. Overall, the present study provides fundamental and technical information on the development of thin-film coating and recovery of Ln-based materials by electrodeposition.

Supplementary Materials: The following are available online at https:/ /www.mdpi.com/2079-6 412/11/1/100/s1, Figure S1: Cyclic voltammetry profiles for $10 \mathrm{mM} \mathrm{Ln(III)} \mathrm{ions} \mathrm{in} 0.1 \mathrm{M} \mathrm{NaClO} 4$ electrolyte on carbon sheets at a scan rate of $200 \mathrm{mV} \cdot \mathrm{s}^{-1}$ and a schematic of a three-electrode system. Newly appeared curvatures are indicated by a red arrow.

Author Contributions: M.H.J., S.J.P., S.-M.H., Y.S., C.K.R. and D.K.; methodology, M.H.J., S.J.P., S.-M.H., Y.S., C.K.R. and D.K.; validation, M.H.J., S.J.P. and S.-M.H.; formal analysis, M.H.J. and S.J.P.; investigation, Y.S.; resources, M.H.J.; data curation, Y.S.; writing—original draft preparation, Y.S., C.K.R. and D.K.; writing—review and editing, S.-M.H. and Y.S.; visualization, Y.S., D.K. and C.K.R.; supervision, Y.S. and C.K.R.; project administration, Y.S. All authors have read and agreed to the published version of the manuscript.

Funding: This research was funded by a National Research Foundation of Korea (NRF) grant funded by the Ministry of Education, Science, and Technology, Korea (2018M2B2A9065523). The APC was funded by the NRF grant.

Institutional Review Board Statement: Not applicable.

Informed Consent Statement: Not applicable.

Data Availability Statement: The data presented in this study are available in article and supplementary material here.

Conflicts of Interest: The authors declare no conflict of interest.

\section{References}

1. Ricci, P.C. Assessment of crystalline materials for solid state lighting applications: Beyond the rare earth elements. Crystals 2020, 10, 559. [CrossRef]

2. Thomas, S.; Mallet, J; Bahuleyan, B.K.; Molinari, M. Growth of homogeneous luminescent silicon-terbium nanowires by one-step electrodeposition in ionic liquids. Nanomaterials 2020, 10, 2390. [CrossRef] [PubMed]

3. Dai, J.; Yang, Z.; Liu, Q. Rare earth cerium increases the corrosion resistance of NdFeB magnets. Materials 2020, 13, 4360. [CrossRef] [PubMed]

4. Ahn, N.-K.; Swain, B.; Shim, H.-W.; Kim, D.-W. Recovery of rare earth oxide from waste NiMH batteries by simple wet chemical valorization process. Metals 2019, 9, 1151. [CrossRef]

5. Caputo, D.; Casiello, M.; Milella, A.; Oberhauser, W.; Maffezzoli, A.; Nacci, A.; Fusco, C.; D'Accolti, L. Deep control of linear oligomerization of glycerol using lanthanum catalyst on mesoporous silica gel. Catalysts 2020, 10, 1170. [CrossRef]

6. Ushakov, S.V.; Hayun, S.; Gong, W.; Navrotsky, A. Thermal analysis of high entropy rare earth oxides. Materials 2020, $13,3141$. [CrossRef] [PubMed]

7. Cardoso, C.E.D.; Almeida, J.C.; Lopes, C.B.; Trindade, T.; Vale, C.; Pereira, E. Recovery of rare earth elements by carbon-based nanomaterials-A review. Nanomaterials 2019, 9, 814. [CrossRef]

8. Wojcik, G. Sorption behaviors of light lanthanides(III) (La(III), $\mathrm{Ce}(\mathrm{III}), \mathrm{Pr}(\mathrm{III}), \mathrm{Nd}(\mathrm{III}))$ and $\mathrm{Cr}(\mathrm{III})$ using natrolite. Materials 2020, 13, 2256. [CrossRef] [PubMed]

9. Dev, S.; Sachan, A.; Dehghani, F.; Ghosh, T.; Briggs, B.R.; Aggarwal, S. Mechanisms of biological recovery of rare-earth elements from industrial and electronic wastes: A review. Chem. Eng. J. 2020, 397, 124596. [CrossRef]

10. Binnemans, K.; Jones, P.T.; Blanpain, B.; Gerven, T.V.; Yang, Y.; Walton, A.; Buchert, M. Recycling of rare earths: A critical review. J. Cleaner. Prod. 2013, 51, 1-22. [CrossRef]

11. Jha, M.K.; Kumari, A.; Panda, R.; Kumar, K.R.; Yoo, K.; Lee, J.Y. Review on hydrometallurgical recovery of rare earth metals. Hydrometallurgy 2016, 165, 2-26. [CrossRef]

12. Binnemans, K.; Jones, P.T. Perspectives for the recovery of rare earths from end-of-life fluorescent lamps. J. Rare Earths 2014, 32, 195-200. [CrossRef]

13. Yurramendi, L.; Gijsemans, L.; Forte, F.; Aldana, J.L.; Río, C.d.; Binnemans, K. Enhancing rare-earth recovery from lamp phosphor waste. Hydrometallurgy 2019, 187, 38-44. [CrossRef]

14. Choi, E.-Y.; Jeong, S.M. Electrochemical processing of spent nuclear fuels: An overview of oxide reduction in pyroprocessing technology. Prog. Nat. Sci. 2015, 25, 572-582. [CrossRef] 
15. Yang, D.-W.; Liu, Y.-L.; Yin, T.-Q.; Jiang, S.-L.; Zhong, Y.-K.; Wang, L.; Li, M.; Chai, Z.-F.; Shi, W.-Q. Application of binary Ga-Al alloy cathode in U separation from Ce: The possibility in pyroprocessing of spent nuclear fuel. Electrochim. Acta 2020, 353, 136449. [CrossRef]

16. Song, Z.; Zhang, H.; Fu, X.; Lin, J.; Shen, M.; Wang, Q.; Duan, S. Effect of current density on the performance of $\mathrm{Ni}^{-\mathrm{P}-\mathrm{ZrO}} \mathrm{Z}_{2}-\mathrm{CeO} 2$ composite coatings prepared by jet-electrodeposition. Coatings 2020, 10, 616. [CrossRef]

17. Bourbos, E.; Karantonis, A.; Sygellou, L.; Paspaliaris, I.; Panias, D. Study of Nd electrodeposition from the aprotic organic solvent dimethyl sulfoxide. Metals 2018, 8, 803. [CrossRef]

18. Li, N.; Chen, W.; Lu, L.; Gao, C. Electrodeposition behavior of polycrystalline Ni-Mo-La composite in alkaline solution. Coatings 2018, 8, 299. [CrossRef]

19. Park, S.J.; Joo, M.H.; Hong, S.-M.; Kang, J.-G.; Rhee, C.K.; Lee, S.W.; Sohn, Y. Electrochemical Eu(III) behaviors and Eu oxysulfate recovery over terpyridine-functionalized indium tin oxide electrode. Inorg. Chem. Front. 2020. [CrossRef]

20. Joo, M.H.; Park, S.J.; Hong, S.M.; Rhee, C.K.; Sohn, Y. Electrochemical recovery and behaviors of rare earth (La, Ce, Pr, Nd, Sm, $\mathrm{Eu}, \mathrm{Gd}, \mathrm{Tb}, \mathrm{Dy}, \mathrm{Ho}, \mathrm{Er}, \mathrm{Tm}$, and $\mathrm{Yb}$ ) ions on Ni sheets. Materials 2020, 13, 5314. [CrossRef]

21. Therese, G.H.A.; Kamath, P.V. Electrochemical synthesis of metal oxides and hydroxides. Chem. Mater. 2000, 12, 1195-1204. [CrossRef]

22. Bocchetta, P.; Santamaria, M.; Di Quarto, F. From ceria nanotubes to nanowires through electrogeneration of base. J. Appl. Electrochem. 2009, 39, 2073-2081. [CrossRef]

23. Santamaria, M.; Asaro, L.; Bocchetta, P.; Megna, B.; Di Quarto, F. Electrodeposition of $\mathrm{CeO}_{2}$ and Co-doped CeO $\mathrm{C}_{2}$ nanotubes by cyclic anodization in porous alumina membranes. ECS Electrochem. Lett. 2013, 2, D29. [CrossRef]

24. Gu, J.I.; Lee, J.; Rhee, C.K.; Sohn, Y. Enhanced electrochemical hydrogen eVolution over defect-induced hybrid $\mathrm{MoO}_{3} / \mathrm{Mo}_{3} \mathrm{O}_{9} \cdot \mathrm{H}_{2} \mathrm{O}$ microrods. Appl. Surf. Sci. 2019, 469, 348-356. [CrossRef]

25. Bai, L.; Ge, Y.; Bai, L. Boron and nitrogen Co-doped porous carbons synthesized from polybenzoxazines for high-performance supercapacitors. Coatings 2019, 9, 657. [CrossRef]

26. NIST DTSA-II Software. Available online: https:/ / cstl.nist.gov/div837/837.02/epq/dtsa2/ (accessed on 10 December 2020).

27. Wu, X.; Li, J.-G.; Zhu, Q.; Liu, W.; Li, J.; Li, X.; Sun, X.; Sakka, Y. One-step freezing temperature crystallization of layered rare-earth hydroxide $\left(\mathrm{Ln}_{2}(\mathrm{OH})_{5} \mathrm{NO}_{3} \cdot n \mathrm{H}_{2} \mathrm{O}\right)$ nanosheets for a wide spectrum of $\mathrm{Ln}(\mathrm{Ln}=\mathrm{Pr}-\mathrm{Er}$, and $\mathrm{Y})$, anion exchange with fluorine and sulfate, and microscopic coordination probed via photoluminescence. J. Mater. Chem. C 2015, 3, 3428-3437. [CrossRef]

28. Kang, J.-G.; Min, B.-K.; Sohn, Y. Synthesis and characterization of $\mathrm{Gd}(\mathrm{OH})_{3}$ and $\mathrm{Gd}_{2} \mathrm{O}_{3}$ nanorods. Ceram. Int. 2015, 41, 1243-1248. [CrossRef]

29. Rutten, O.W.J.S.; Van Sandwijk, A.; Van Weert, G. The electrochemical reduction of nitrate in acidic nitrate solutions. J. Appl. Electrochem. 1999, 29, 87-92. [CrossRef]

30. Pous, N.; Koch, C.; Colprim, J.; Puig, S.; Harnisch, F. Extracellular electron transfer of biocathodes: Revealing the potentials for nitrate and nitrite reduction of denitrifying microbiomes dominated by Thiobacillus sp. Electrochem. Commun. 2004, 49, 93-97. [CrossRef]

31. Chen, Y.; Zhang, Y.-H.; Zhao, L.-Z. ATR-FTIR spectroscopic studies on aqueous $\mathrm{LiClO}_{4}, \mathrm{NaClO}_{4}$, and $\mathrm{Mg}\left(\mathrm{ClO}_{4}\right)_{2}$ solutions. Phys. Chem. Chem. Phys. 2004, 6, 537-542. [CrossRef]

32. Kang, J.-G.; Kim, Y.-I.; Cho, D.W.; Sohn, Y. Synthesis and physicochemical properties of $\mathrm{La}(\mathrm{OH})_{3}$ and $\mathrm{La}_{2} \mathrm{O}_{3}$ nanostructures Mater. Sci. Semicond. Process. 2015, 40, 737-743. [CrossRef]

33. Khan, M.M.; Ansari, S.A.; Pradhan, D.; Han, D.H.; Lee, J.; Cho, M.H. Defect-induced band gap narrowed CeO 2 nanostructures for visible light activities. Ind. Eng. Chem. Res. 2014, 53, 9754-9763. [CrossRef]

34. Kang, J.-G.; Min, B.-K.; Sohn, Y. Physicochemical properties of praseodymium hydroxide and oxide nanorods. J. Alloys Compd. 2015, 619, 165-171. [CrossRef]

35. Jeon, S.H.; Nam, K.; Yoon, H.J.; Kim, Y.-I.; Cho, D.W.; Sohn, Y. Hydrothermal synthesis of $\mathrm{Nd}_{2} \mathrm{O}_{3}$ nanorods. Ceram. Int. 2017, 43, 1193-1199. [CrossRef]

36. Kang, J.-G.; Min, B.-K.; Sohn, Y. Synthesis and characterization of $\mathrm{Sm}(\mathrm{OH})_{3}$ and $\mathrm{Sm}_{2} \mathrm{O}_{3}$ nanoroll sticks. J. Mater. Sci. 2015, 50, 1958-1964. [CrossRef]

37. Kang, J.-G.; Jung, Y.; Min, B.-K.; Sohn, Y. Full characterization of $\mathrm{Eu}(\mathrm{OH})_{3}$ and $\mathrm{Eu}_{2} \mathrm{O}_{3}$ nanorods. Appl. Surf. Sci. 2014, 314, 158-165. [CrossRef]

38. Sohn, Y. Structural and spectroscopic characteristics of terbium hydroxide/oxide nanorods and plates. Ceram. Int. 2014, 40, 13803-13811. [CrossRef]

39. Kang, J.-G.; Gwag, J.S.; Sohn, Y. Synthesis and characterization of $\mathrm{Dy}(\mathrm{OH})_{3}$ and $\mathrm{Dy}_{2} \mathrm{O}_{3}$ nanorods and nanosheets. Ceram. Int. 2015, 41, 3999-4006. [CrossRef]

40. Lee, H.I.; Lee, S.W.; Rhee, C.K.; Sohn, Y. Paramagnetic $\mathrm{Ho}_{2} \mathrm{O}_{3}$ nanowires, nano-square sheets, and nanoplates. Ceram. Int. 2018, 44, 17919-17924. [CrossRef]

41. Yoon, H.J.; Lee, J.; Kim, Y.-I.; Cho, D.W.; Sohn, Y. Synthesis and characterization of $\mathrm{Er}_{2} \mathrm{O}_{3}$ nanorods and nanosheets. Ceram. Int. 2017, 43, 2069-2075. [CrossRef]

42. Lee, S.W.; Park, S.K.; Min, B.-K.; Kang, J.-G.; Sohn, Y. Structural/spectroscopic analyses and $\mathrm{H}_{2} / \mathrm{O}_{2} / \mathrm{CO}$ responses of thulium(III) oxide nanosquare sheets. Appl. Surf. Sci. 2014, 307, 736-743. [CrossRef]

43. Sohn, $\mathrm{Y} . \mathrm{Yb}_{2} \mathrm{O}_{3}$ nanowires, nanorods and nano-square plates. Ceram. Int. 2018, 44, 3341-3347. [CrossRef] 
44. NIST X-ray Photoelectron Spectroscopy Database, Version 4.1 (National Institute of Standards and Technology, Gaithersburg, 2012). Available online: http:/ / srdata.nist.gov/xps / (accessed on 1 December 2020).

45. Pawlik, N.; Szpikowska-Sroka, B.; Pisarski, W.A. Energy transfer study on $\mathrm{Tb}^{3+} / \mathrm{Eu}^{3+}$ co-activated sol-gel glass-ceramic materials containing $\mathrm{MF}_{3}(\mathrm{M}=\mathrm{Y}, \mathrm{La})$ nanocrystals for NUV optoelectronic devices. Materials 2020, 13, 2522. [CrossRef] [PubMed] 